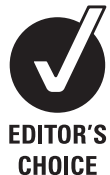

Department of Pathology, Democritus University of Thrace Medical School, and University General Hospital of

Alexandroupolis,

Alexandroupolis, Greece

\section{Correspondence to}

Efthimios Sivridis, Department of Pathology, Democritus University of Thrace Medical School, and University General Hospital of Alexandroupolis, PO Box 128, Alexandroupolis 68100, Greece: esivrid@med.duth.gr

Accepted 18 January 2011 Published Online First 17 February 2011

\title{
The pathogenesis of endometrial carcinomas at menopause: facts and figures
}

\author{
Efthimios Sivridis, Alexandra Giatromanolaki
}

ABSTRACT

Almost a third of the life of a woman is now postmenopausal, and during this period over $80 \%$ of endometrial carcinomas develop. This is by far the most common gynaecological malignancy in the industrialised world and, probably, the less completely understood with regard to its pathogenesis after the menopause. For while it is generally thought that these neoplasms are non-oestrogen-induced, we are, at the same time, informed that oestrogenic stimulation is continuous during menopause through increases to oestrone formation in the adipose tissue from androgens of adrenal and ovarian origin. Furthermore, the postmenopausal endometrium has been typified as atrophic, which is indeed true, but is also implied as being inactive, which in fact it is not; in most cases, the postmenopausal endometrium appears to be weakly proliferative with potential to give rise to an endometrial carcinoma. It is also assumed that postmenopausal endometrial tumours are predominantly of serous papillary and clear cell type, and, in general, they are not well-differentiated endometrioid carcinomas; in reality, no more than $15 \%$ are serous papillary and clear cell carcinomas, and no less than $55 \%$ are well-differentiated endometrioid neoplasms. The overall prognosis is presumed to be poor, yet postmenopausal patients harbouring well-differentiated endometrioid carcinomas have the same excellent prognosis as those premenopausal women having endometrioid tumours of similar grade and stage. This brief account of endometrial carcinogenesis at menopause re-evaluates these issues and, in the light of new and old evidence, proposes the separation of $\mathrm{G} 1$ endometrioid adenocarcinomas (low-grade tumours) from all others (high-grade tumours).

\section{INTRODUCTION}

The study of endometrial carcinoma at menopause presents an interesting challenge. The tumour is, on the whole, the commonest gynaecological malignancy in the industrialised world, ${ }^{1-3}$ comprising $4 \%$ of all cancers in women, and a lifetime risk of $2-3 \%{ }^{4}$ It is a disease of ageing, with over $80 \%$ of cases occurring during the menopause..$^{5-7}$

This is a paradox, for endometrial carcinomas are hormone-dependent tumours and, as such, have been associated with high circulating levels of unopposed oestrogens (oestrogens in the absence of progesterone). Yet, at the time these tumours most commonly occur, that is during menopause, oestrogen secretion is waning. To acknowledge that prolonged oestrogenic stimulation of the endometrium occurs in carcinomas developing in the young (type I carcinomas), while postmenopausal women simply lack such a stimulus (type II carcinomas), ${ }^{8-11}$ would have us understand not what the mechanism of the disease is in older women, but what it is not.

As a consequence of ovarian failure, endometrial carcinomas during menopause have been presumed to originate from a background of endometrial atrophy and inactivity. ${ }^{8-11}$ There is little doubt that the postmenopausal endometria are atrophic, but this does not necessarily mean that they are also inactive-a contention that needs further thought. How could a state of 'inertia' give rise to a new growth, even if this is an abortive growth?

It is true that serous papillary and clear cell carcinomas, which are hosted almost exclusively by the postmenopausal uteri, are lethal tumours. ${ }^{12-14}$ The question remains, of course, how prevalent these tumours are to affect an overall prognosis? And what is the frequency of other postmenopausal endometrial tumours that are known to have a much better outcome? These are issues that are becoming increasingly important.

This review will focus on endometrial carcinomas developing during menopause, not simply because they are more common, but because their pathogenesis is less completely understood; the pathogenesis of tumours arising in young women during their reproductive years has been precisely delineated and requires no further consideration. ${ }^{12-15}$

\section{PATHOGENETIC MECHANISM IN ENDOMETRIAL CARCINOMAS AT MENOPAUSE: YET AGAIN, AN OESTROGENIC MILIEU}

The belief that postmenopausal endometrial carcinogenesis is not oestrogen induced rests largely upon the paucity of ovarian function that follows the menopause and the presence of a thin atrophic endometrium. This may all be true, but should not be allowed to detract from the fact that oestrogen production continues after the menopause. ${ }^{16} 17$ For indeed, in addition to oestrogens being secreted by the developing ovarian follicle during reproductive life, they are also secreted during the menopause from androgens produced by the adrenal glands and the non-specialised ovarian stroma. ${ }^{16} 18$ The secretion, mainly in the form of androstenedione and testosterone, is increased notably during this period, ${ }^{20-22}$ in parallel with an increased conversion of androgens to oestrone. ${ }^{23} 24$

The reaction takes place in peripheral tissues, mainly in adipose tissue, through the cytochrome P450 aromatase, and has been estimated to be 3-5 times above normal levels of secretion ${ }^{23} 24$; it is further enhanced with increasing body weight and advanced age..$^{1825-29}$ The extrafolliclular oestrogens produced can freely diffuse to the endometrium as 
biologically active hormones, as they are unbound to sexhormone-binding globulin. ${ }^{20} 30$ This is because the level of sexhormone-binding globulin is decreased in obese postmenopausal women. ${ }^{16} 30-36$ It is worth mentioning that although all postmenopausal women are capable of converting androgens to oestrogens under 'physiological' conditions, ${ }^{37}$ only those that have a high efficiency in doing so are at risk of developing endometrial cancer ${ }^{38}{ }^{39}$; indeed, extrafollicular oestrogen concentrations are significantly higher in women with endometrial carcinomas relative to healthy controls. ${ }^{22} 2634$ It is possible that some of the conversion occurs in the endometrium, through endometrial aromatase cytochrome P450, thus increasing oestrogen concentrations at the endometrial level. ${ }^{21} 40$

The mechanism of conversion of androgen to oestrogen assumes a dominant role under the pathological conditions of oestrogen-secreting ovarian neoplasms, mainly granulosa and thecal cell tumours, and in a background of cortical stromal hyperplasia and hyperthecosis. ${ }^{21}{ }^{41}$ Nulliparity or low parity, which is associated with failure of ovulation, and persistence of the mature follicle and prolonged high oestrogen levels without corpus luteum formation, may enhance the possibility of developing endometrial carcinoma by increasing the exposure time of the endometrium to endogenous oestrogens. ${ }^{42}$

It is, however, only the therapeutic intervention in the uterus, specifically in the form of hormone replacement therapy, which illustrates clearly the role of oestrogens in postmenopausal endometrial carcinogenesis. ${ }^{35} 38$ 43-47 This practice, which simulates precisely the naturally occurring 'prolonged oestrogenic stimulation of the endometrium, unopposed by progesterone action', has been associated with an 8-fold to 15-fold increase in incidence of endometrial carcinoma. ${ }^{48-53}$ Most interestingly, the risk was reduced considerably with the addition of progestins. ${ }^{45} 54-56$

It is thus apparent that an oestrogenic milieu does exist in the postmenopausal endometrium and may account, to a certain extent, for the observed increases of endometrial cancer in older women. ${ }^{34} 3857$ Obesity, as the driving force of the conversion mechanism, has been implicated in about $40 \%$ of all endometrial cancer cases in postmenopausal women. ${ }^{58-62}$ Notably, oestrone and oestradiol concentrations have been shown to be significantly higher in women with endometrial cancer compared with healthy women, and also in endometrial carcinoma cell lines compared with unaffected controls. ${ }^{63}$ Oestrone, while a weak oestrogen, has proved to be more effective than oestradiol and oestriol in promoting endometrial carcinomas in mice. ${ }^{64}$

\section{THE DYNAMICS OF AN ATROPHIC, BUT PROLIFERATING/NON- INACTIVE POSTMENOPAUSAL ENDOMETRIUM}

Oestrogen drive stimulation appears to be a common pathogenetic mechanism in postmenopausal endometrial carcinomas, particularly when it acts continuously and in relatively increased concentrations on its target tissue: the endometrium. 535385965 But what are the changes that a 'physiological' uterine mucosa assumes following the decline of ovarian function?

At first, the non-cycling, yet normal, asymptomatic postmenopausal endometrium becomes gradually atrophic, assuming a shallow uterine mucosa, $2.2 \mathrm{~mm}$ thick, with loss of distinction between the basal layer and the functional layer. ${ }^{65}$ The endometrial glands may initially retain some proliferative activity, albeit weak, ${ }^{65-67}$ but, with further decline of oestrogen secretion, the uterine mucosa becomes functionally inactive. ${ }^{65}$ It is composed of small tubular glands, widely spaced, and these are lined by cuboidal indeterminate epithelium, showing neither secretory nor proliferative activity; the stroma is dense and fibrous. Finally, with complete absence of ovarian function, ${ }^{68}$ the endometrium falls into cystic atrophy, ${ }^{69}$ having a thin uterine mucosa, cystically dilated endometrial glands, and a flattened inactive epithelium.

The loss of the negative feedback of oestrogens on the hypothalamus, combined with the loss of the restraining action of inhibin $\mathrm{B}$ on the secretion of follicle-stimulating hormone, provoke a marked increase in serum gonadotropins, predominantly pituitary follicle stimulating hormone. ${ }^{70-72}$ This, in turn, stimulates the production of androgens, mainly androstenedione and testosterone, by the non-specialised ovarian stroma. Peripheral conversion of ovarian and adrenal androgens to oestrone through aromatisation in the adipose tissues becomes the primary source of endogenous oestrogens in postmenopausal women and may be sufficient to stimulate the endometrium. ${ }^{59}$ Subject to these conditions, the endometrium, while remaining atrophic, abandons its state of inertia and resumes its weak proliferative activity, ${ }^{66} 6773$ exemplified by focal proliferation of endometrial glands, with moderate tortuosity, pseudostratification and infrequent mitoses.

In reality, most asymptomatic non-cycling endometria are thin and atrophic, ${ }^{65-67}$ but only half of the cases are inactive. ${ }^{65}$ The remaining show a weak proliferative activity, ${ }^{65-67}$ indicative of an endometrium that receives, and apparently responds to, continuous low level oestrogenic messages. This was inferred from the presence of morphologically active endometrial glands, having a full complement of oestrogen receptor, progesterone receptor and epidermal growth factor receptor, and an increased proliferative activity (MIB-1), set in a highly vascular endometrial stroma. 657475

The implications of these findings are obvious. Under the influence of relatively high levels of unopposed oestrogenic stimulation, the postmenopausal endometrium may develop mild architectural changes and turn into the so-called disordered proliferative endometrium, ${ }^{69} 73$ or it may display increasing degrees of architectural and cytological atypias, and take the form of atypical endometrial hyperplasia (endometrial intraepithelial neoplasia) $66 \quad 677677$ or endometrial intraepithelial carcinoma, ${ }^{78} 79$ from which an endometrial carcinoma can develop.

These observations may explain the latent potential that an atrophic, but proliferating (non-inactive), endometrium may have to assume various forms of postmenopausal proliferative activity and through them, if not directly, give rise to an endometrial adenocarcinoma. ${ }^{65}$

\section{THE PREVALENCE OF THE VARIOUS TUMOUR CELL TYPES: A CLASSIFICATION SCHEME WITH PROGNOSTIC VALUE}

It is true that endometrial carcinomas occurring during the reproductive years are all, or nearly all, well-differentiated endometrioid adenocarcinomas (so-called type I carcinomas). However, the reverse contention may not be necessarily correct as, indeed, only a quarter of the tumours developing after the menopause are non-endometrioid carcinomas. In addition, it is not always realised that as many as $55 \%$ of endometrial carcinomas at menopause are also of the G1 endometrioid type, (figure $1 \mathrm{~A}$ ) and a further $20 \%$ are G2/G3 endometrioid tumours (figure 1B). ${ }^{5} 15738081$ The prototypes of non-endometrioid carcinomas (type II carcinomas), the serous papillary (figure 1C) and the clear cell (figure 1D) tumours, share no more than $15 \%$ of the total, ${ }^{13} 1482-88$ and there is, of course, a group of around $10 \%$ of rather unusual types of nonendometrioid carcinomas. $^{81}$ (box 1). 
Figure 1 Basic histological forms of endometrial carcinoma at menopause. (A) Grade 1 endometrioid adenocarcinoma, (B) grade 3 endometrioid carcinoma, (C) serous papillary carcinoma, (D) clear cell carcinoma.
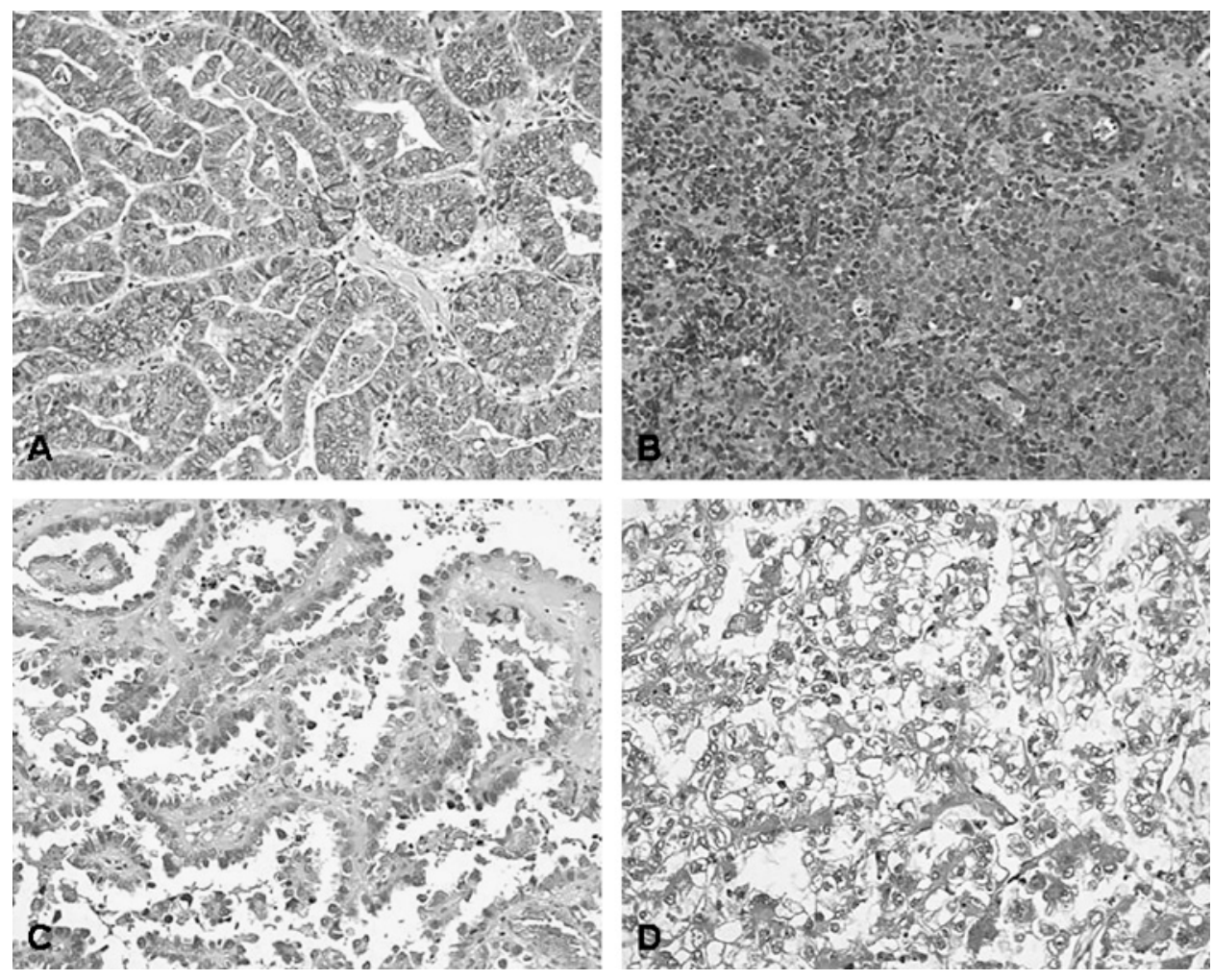

(1)

Obviously, these data have an impact on patient survival. The many well-differentiated endometrioid adenocarcinomas originating from an atrophic postmenopausal endometrium are similar in all respects to those endometrioid adenocarcinomas of equal grade and stage that are associated with atypical hyperplasia in young premenopausal women ${ }^{5}{ }^{73}$; they all have an almost excellent prognosis, with reported 5-year survival rates varying from $87 \%$ to $97 \% .{ }^{89} 90$ The serous papillary and clear cell carcinomas, on the other hand, are aggressive tumours that have an increased metastatic potential, high tendency for relapses, and a 5 -year survival rate that may be as low as $15 \%$, 12 91 although the usual survival rate quoted has varied from $30 \%$ to $68 \%{ }^{12} 8592-100$ With the exception of mucinous carcinomas (see below), the moderately and poorly differentiated endometrioid carcinomas and the various non-endometrioid types have a similar ominous clinical course (box 1). ${ }^{101-103}$ Recently, Soslow et al who investigated a series of high-grade endometrial neoplasms of different histological type, namely G3 endometrioid, serous papillary and clear cell carcinomas, found that they were all associated with an almost similar clinical outcome; the corresponding 5 -year survival rates of $45 \%, 36 \%$ and $50 \%$ were not statistically significant. ${ }^{103}$

There can be no doubt that a diverse collection of lethal tumours, such as the serous papillary, the clear cell, other nonendometrioid tumours, together with the G2/G3 endometrioid carcinomas, would make the survival of postmenopausal women worse. Yet, it has to be admitted that these tumours attracted a degree of attention disproportionate to their frequency, while the many well-differentiated endometrioid adenocarcinomas of the postmenopausal age, with an unquestionably favourable prognosis, have been almost totally ignored. Thus, the longstanding assertion that endometrial carcinomas developing during menopause are of poor prognosis is too wide a generalisation.

It has been thus far illustrated that endometrial carcinomas occurring at menopause form a heterogeneous group of tumours, the prognosis of which depends on the histological type (whether endometrioid or non endometrioid) (box 1) and on the degree of differentiation (whether G1, G2 or G3) (box 2). ${ }^{104-107}$ However, grading of endometrioid adenocarcinomas can be highly subjective, particularly in distinguishing between

Box 1 Classification of endometrial carcinomas at menopause

\section{Low-grade endometrial adenocarcinomas}

- Endometrioid

- Usual type

- With squamous differentiation

- Papillary

- Secretory

- Ciliated cell

- Sertoliform

- With trophoblastic differentiation

- Oxyphil cell

- Non-endometrioid

- Mucinous

High-grade endometrial carcinomas

- Endometrioid

- Solid type

- Non-endometrioid

- Serous papillary

- Clear cell

- Squamous cell

- Transitional cell

- Mixed types

- Undifferentiated

- Verrucous

- 'Glassy cell' 
Box 2 The three-level FIGO grading system for endometrial adenocarcinomas of the endometrioid cell type compared with proposed binary tumour grading systems

1988 FIGO grading ${ }^{* 145}$

- G1: composed almost exclusively of well-formed glands; $\leq 5 \%$ solid (non-squamous) component

- G2: $6-50 \%$ solid (non-squamous) component

- G3: $>50 \%$ solid (non-squamous) component; lacks well formed glands

Taylor et al (1999) $)^{112}$

- Low grade: $\leq 20 \%$ solid (non squamous) growth

- High grade: $>20 \%$ solid (non squamous) growth

Lax et al (2000) $\dagger^{111}$

- Low grade: $\leq 50 \%$ solid growthł, expansive/pushing tumour border, no evidence of tumour cell necrosis

- High grade: $>50 \%$ solid growth $\neq$, infiltrative growth pattern, tumour cell necrosis

Scholten et al (2004) 110

- Low grade: $\leq 50 \%$ solid growth $\neq$

- High grade: $>50 \%$ solid growth $\neq$

Alkushi et al (2005) $\dagger^{109}$

- Low grade: predominance of glandular pattern, mild to moderate atypia, $\leq 6$ mitoses per HPF

- High grade: Predominance of papillary or solid growth, severe nuclear atypia, $>6$ mitoses per HPF

FIGO, International Federation of Gynecology and Obstetrics; HPF, high-power field.

*Notes on FIGO grading: notable nuclear atypia, inappropriate for the architectural grade (particularly pleomorphism and prominent nucleoli), raises the grade from 1 to 2 or from 2 to $3^{146}$; by convention, serous papillary and clear cell carcinomas are considered grade 3; adenocarcinomas with squamous differentiation are graded according to the nuclear grade of the glandular component.

†High grade if at least two of the three criteria are present.

†Irrespective of squamous or non-squamous differentiation.

International Federation of Gynecology and Obstetrics (FIGO) grade G1 ( $<5 \%$ solid growth) and FIGO G2 ( $>5 \%$ solid growth) tumours $^{73} 105$ and, indeed, many G2 endometrioid adenocarcinomas may appear less aggressive than G1 endometrioid adenocarcinomas. Nevertheless, it has been suggested that a binary grading system that divides endometrial tumours into low-grade and high-grade is more effective in assessing prognosis and has greater reproducibility than the presently used three-tier FIGO grading system. This has been claimed for all two-tier grading systems proposed, ${ }^{108-112}$ whether based solely on the proportion of solid growth, ${ }^{110} 112$ or on solid growth and additional histological criteria, such as mode of invasion and tumour cell necrosis ${ }^{111}$ or nuclear atypia and mitotic activity ${ }^{109}$ (box 2) (for a full discussion, see the recent review by Clarke and Gilks ${ }^{105}$ ).

In this context, the endometrial carcinomas may be conveniently divided, in terms of prognosis, into groups of low-grade and high-grade. The first, and apparently larger, group of tumours is represented by the well-differentiated endometrioid carcinomas and the mucinous tumours; the mucin-secreting adenocarcinomas have a remarkable resemblance to G1 endometrioid neoplasms, and occur with a frequency of $0.6 \%$ to $5 \%{ }^{87}$ and a 5-year survival rate of $95 \% .{ }^{10} 81113-116$ The second group of endometrial carcinomas comprises the high-grade serous papillary and the clear cell carcinomas, the G2 and G3 endometrioid neoplasms, and the various unusual types of non-endometrioid carcinomas. This system is meant to be prognostically meaningful and may lead to individualisation of treatment. Box 1 outlines the taxonomic scheme proffered, and table 1 summarises the specific features of the various tumours.

\section{GENETIC SUBGROUPS OF ENDOMETRIAL CARCINOMA: WHAT IS THE MESSAGE?}

Our option to separate G1 endometrioid adenocarcinomas from those of G2/3 and the non-endometrioid tumours appears to be also justified in terms of molecular genetic changes. In the first instance, it was shown that endometrioid and serous papillary carcinomas express genetic aberrations with different frequencies (table 2). The endometrioid adenocarcinomas display, as a whole, a high incidence of mutations in the PTEN ${ }^{117-120}$ and K-ras genes, ${ }^{121-123}$ and often contain microsatellite instability ${ }^{122}{ }^{124-127}$ and a near diploid karyotype. ${ }^{128-130}$ In contrast, the serous papillary carcinomas carcinomas rarely, if ever, exhibit PTEN and K-ras mutations, microsatellite instability or a diploid karyotype, but are more likely to have p53 mutations ${ }^{122}{ }^{131-135}$ and a non-diploid (aneuploid) karyotype. ${ }^{128-130}$

There has been some evidence, however, that in addition to such genetic differences existing between various types of endometrial carcinoma (ie, serous papillary versus

Table 1 Specific features of low-grade and high-grade endometrial carcinomas developing during menopause

\begin{tabular}{lll}
\hline Feature & Low-grade endometrial carcinoma & High-grade endometrial carcinoma \\
\hline Age & Perimenopausal and postmenopausal years & Perimenopausal and postmenopausal years \\
$\begin{array}{l}\text { Tumour-free endometrium adjacent } \\
\text { to carcinoma }\end{array}$ & $\begin{array}{l}\text { Atrophic (but not inactive); usually weakly } \\
\text { proliferative }\end{array}$ & Atrophic (but not inactive); usually weakly proliferative \\
Pathogenesis & Extra-ovarian oestrone stimulation & \\
Frequency & Common (about 55\%) & Extra-ovarian oestrone stimulation \\
Precursor lesion & Rarely, but if present: atypical endometrial & Less common (about 45\%) \\
& hyperplasia & Presumed to be less uncommon: endometrial intraepithelial \\
Histological type & Endometrioid carcinoma G1 (55\%), mucinous & carcinoma/endometrial glandular dysplasia ('p53 signatures') \\
cifferentiation & carcinoma G1 & Serous papillary carcinoma (10\%), clear cell carcinoma (5\%), \\
Receptor state & G1 & G2-G3 \\
Myometrial invasion & ER rich, PR rich & ER rich or ER poor, PR rich or PR poor \\
Lymphatic invasion & Nil to inner $1 / 3$ & Inner $1 / 3$ to 3/3 \\
Stage & Less common & Common \\
Prognosis & I & I-IV \\
\hline
\end{tabular}

$E R$, oestrogen rceptor; PR, progesterone receptor. 
Table 2 The main gene expression profiles in endometrioid and serous papillary carcinomas of the endometrium

\begin{tabular}{llll}
\hline & $\begin{array}{l}\text { Endometrioid } \\
\text { carcinoma }\end{array}$ & $\begin{array}{l}\text { Serous } \\
\text { papillary carcinoma (\%) }\end{array}$ & References \\
\hline PTEN mutations & $37-83$ & $0-5$ & $117-120$ \\
K-ras mutations & $10-26$ & $0-2$ & $121-123$ \\
Microsatellite instability & $15-28$ & 0 & $122124-127$ \\
$\beta$-Catenin & $14-44$ & $0-5$ & $144147-149$ \\
p53 & $14-20$ & $53-96$ & $122131-135$ \\
Aneuploidy & $10-18$ & $85-95$ & $128-130$ \\
E-cadherin & $10-20$ & $80-90$ & $139-141$ \\
\hline
\end{tabular}

endometrioid), they also exist between the various grades of endometrioid neoplasms. For example, the high-grade endometrioid carcinomas tend to follow the molecular patterns expressed by the serous papillary carcinomas rather than those of low-grade endometrioid neoplasms. More specifically, p53 mutations have been reported to occur in $93 \%$ of serous papillary carcinomas, but in only $17 \%$ of endometrioid carcinomas. Yet, endometrioid carcinomas, assessed by tumour grade, have been found to express p53 mutations only if they are high-grade: G3, 43\%; G2, 8\%; G1, 0\%. ${ }^{122} 134136$ In another study, p53 mutations were recorded in $82 \%$ of serous papillary carcinomas, $57 \%$ in G3 endometrioid disease, and 14\% in the combined group of G1/G2 endometrioid carcinomas. ${ }^{134}$

It is worth noting that p53 defects were less frequent in clear cell carcinomas than in serous papillary tumours, ${ }^{114}$ and any difference in p53 expression between clear cell and G3 endometrioid carcinomas was not statistically significant. ${ }^{114}$ This tendency was repeated by immunohistochemistry. Overexpression of p53 was more frequent in non-endometrioid than in endometrioid carcinomas (38\% versus $13 \%$, respectively); however, when endometrioid carcinomas were assessed as a function of tumour differentiation, the G3 endometrioid carcinomas almost reached the frequency of the non-endometrioid tumours (36\% versus 38\%); the reported values for G2 and G1 endometrioid carcinomas were $20 \%$ and $8 \%$, respectively. ${ }^{137}$

Likewise, the genetic aberrations have been found to be more frequent and more complex in serous papillary than in endometrioid carcinomas, with means of 5.7 versus 1.5 aberrations per tumour, respectively. ${ }^{138}$ However, when endometrioid carcinomas were assessed as a function of tumour grade, the mean numbers of changes per sample were 2.3 for G3, 2.2 for G2, and 0.73 for G1 carcinomas.

E-cadherin, which is generally considered as a suppressor of tumour progression, ${ }^{139-141}$ has been found to be associated with reduced expression in serous papillary, clear cell and the G3 endometrioid carcinomas, when the latter were evaluated by tumour grade. ${ }^{124-144}$

Similar trends have been manifested in ploidy-related parameters. Thus, the proportion of non-diploid karyotypes in various studies ranged from $70-95 \%$ in serous papillary carcinomas, and from $24-70 \%$ in G3 endometrioid carcinomas ${ }^{128-130}$; in fact, the highest values of G3 endometrioid tumours have been identified with the lowest values of serous papillary carcinomas. The corresponding figures for G2 and G1 endometrioid carcinomas were $11-14 \%$ and $9-11 \%$, respectively. ${ }^{128} 130$

Others have found that G3 endometrioid carcinomas may even exceed the serous papillary carcinomas in frequency of ploidy-related parameters; tetraploidy, for example, has been reported as being expressed in $21 \%$ of G3 endometrioid carcinomas versus $18 \%$ of serious papillary tumours. ${ }^{130}$ The corresponding tetraploid values for G2 and G1 endometrioid carcinomas were $5 \%$ and $3 \%$, respectively. ${ }^{130}$ It appears, therefore, that the proposed taxonomy for endometrial carcinomas has considerable merit in this respect.

\section{CONCLUDING REMARKS}

Despite the decline in ovarian function that follows menopause, oestrogen, but not progesterone, synthesis continuous during the postmenopausal years through increases to oestrone formation from androgens of adrenal and ovarian origin. The reaction, which occurs in the adipose tissue and enhances with increasing body weight and advanced age, may occasionally produce relatively high oestrogen concentrations.

Under such conditions, the endometrium, while remaining thin and atrophic, assumes a weak proliferative activity, which is capable of giving genesis to various forms of proliferation and potentially to endometrial carcinoma. Indeed, there is a dramatic increase in the incidence of endometrial carcinoma during the postmenopausal years; this may suggest that oestrone, a weak oestrogen, may play the same pathogenetic role in the development of endometrial carcinoma as does a potent oestrogen, oestradiol, in young premenopausal women. If this is true, as it appears, endometrial carcinomas should no longer be regarded as 'oestrogen dependent' (type I carcinomas occurring in premenopausal women) or 'oestrogen independent' (type II carcinomas developing at menopause), but rather as neoplasms of having varying degrees of hormone dependence.

\section{Take-home messages}

- Endometrial carcinoma is predominantly a disease of menopause, but it also arises in a setting of oestrogenic milieu. This should not be considered a paradox, since oestrogens are produced not only by the developing ovarian follicle during the reproductive years, but also at menopause from the peripheral conversion (aromatisation) of androgens produced by the adrenal glands and the non-specialised ovarian stroma. Obesity and advanced age are contributory factors. Oestrogen replacement therapy also plays a major role.

- Postmenopausal oestrogenic stimulation, when somewhat increased, it is associated with an endometrium which, while atrophic, displays a weak proliferative activity; this is the background upon which endometrial carcinoma most commonly arises.

- Serous papillary and clear cell carcinomas (so-called type II carcinomas) are lethal grade 3 tumours, developing almost exclusively during menopause, but these form only $15 \%$ of the total number of tumours. In contrast, the low-grade endometrioid adenocarcinomas, which form nearly $55 \%$ of tumours developing in postmenopausal women, have the same favourable prognosis as do the endometrioid adenocarcinomas of similar grade arising in young premenopausal women (so-called type I carcinomas).

- Thus, endometrial carcinoma, as a postmenopausal disease, is not invariably of poor prognosis, as it is generally assumed, and it will be convenient, and indeed necessary, to separate the low-grade/favourable prognosis endometrioid adenocarcinomas from the high-grade/unfavourable prognosis G2 and 3 endometrioid carcinomas and those of the non-endometrioid type. 


\section{Interactive multiple choice questions}

This JCP review article has an accompanying set of multiple choice questions (MCOs). To access the questions, click on BMJ Learning: Take this module on BMJ Learning from the content box at the top right and bottom left of the online article. For more information please go to: http://jcp.bmj.com/education Please note: the MCOs are hosted on BMJ Learning - the best available learning website for medical professionals from the BMJ Group. If prompted, subscribers must sign into JCP with their journal's username and password. All users must also complete a onetime registration on BMJ Learning and subsequently log in (with a BMJ Learning username and password) on every visit.

In contrast to what it is generally believed, many endometrial carcinomas occurring during the menopause are well-differentiated endometrioid adenocarcinomas having an almost excellent prognosis. The remaining cases are lethal tumours, more or less. Apart from morphology and prognosis, the two groups appear to be different in terms of molecular genetic frequencies. Their taxonomic separation would allow individualisation of treatment.

Competing interests None.

Provenance and peer review Not commissioned; externally peer reviewed.

\section{REFERENCES}

1. AIHW. Australian Institute of Health and Welfare and the Australian Association of Cancer Registries. Cancer in Australia 1999. Canberra: AlHW and Australian Association of Cancer Registries, 2002.

2. Bray F, Dos Santos Silva I, Moller $\mathrm{H}$, et al. Endometrial cancer incidence trends in Europe: underlying determinants and prospects for prevention. Cancer Epidemiol Biomarkers Prev 2005:14:1132-42.

3. Jemal A, Siegel R, Ward E, et al. Cancer statistics, 2009. CA Cancer J Clin 2009:59:225-49.

4. Engelsen IB, Akslen LA, Salvesen HB. Biologic markers in endometrial cancer treatment. APMIS 2009;117:693-707.

5. Sivridis E, Fox H, Buckley C. Endometrial carcinoma: two or three entities? Int $J$ Gynecol Cancer 1998;8:183-8.

6. Trimble CL, Kauderer J, Zaino R, et al. Concurrent endometrial carcinoma in women with a biopsy diagnosis of atypical endometrial hyperplasia: a gynecologic oncology group study. Cancer 2006;106:812-19.

7. Uharcek P. Prognostic factors in endometrial carcinoma. J Obstet Gynaecol Res 2008;34:776-83.

8. Bokhman JV. Two pathogenetic types of endometrial carcinoma. Gynecol Oncol 1983:15:10-17.

9. Deligdisch L, Cohen CJ. Histologic correlates and virulence implications of endometrial carcinoma associated with adenomatous hyperplasia. Cancer 1985:56:1452-5.

10. Deligdisch L, Holinka CF. Progesterone receptors in two groups of endometrial carcinoma. Cancer 1986;57:1385-8.

11. Sherman ME. Theories of endometrial carcinogenesis: a multidisciplinary approach. Mod Pathol 2000;13:295-308.

12. Christopherson WM, Alberhasky RC, Connelly PJ. Carcinoma of the endometrium: I. A clinicopathologic study of clear-cell carcinoma and secretory carcinoma. Cancer 1982; 49:1511-23.

13. Cirisano FD Jr, Robboy SJ, Dodge RK, et al. Epidemiologic and surgicopathologic findings of papillary serous and clear cell endometrial cancers when compared to endometrioid carcinoma. Gynecol Oncol 1999;74:385-94.

14. Trope C, Kristensen GB, Abeler VM. Clear-cell and papillary serous cancer: treatment options. Best Pract Res Clin Obstet Gynaecol 2001;15:433-46.

15. Sivridis E. An Immunohistochemical Study of Endometrial Hyperplasia and Neoplasia. PhD thesis. UK: University of Manchester, 1986.

16. Siiteri PK. Steroid hormones and endometrial cancer. Cancer Res 1978;38:4360-6.

17. Judd HL. Hormonal dynamics associated with the menopause. Clin Obstet Gynecol 1976;19:775-88.

18. Cleland WH, Mendelson CR, Simpson ER. Effects of aging and obesity on aromatase activity of human adipose cells. J Clin Endocrinol Metab 1985; 60:174-7.

19. Sasano H, Harada N. Intratumoral aromatase in human breast, endometrial, and ovarian malignancies. Endocr Rev 1998;19:593-607.

20. Siiteri PK. Adipose tissue as a source of hormones. Am J Clin Nutr 1987;45 (1 Suppl):277-82
21. Nagamani M, Hannigan EV, Dillard EA Jr, et al. Ovarian steroid secretion in postmenopausal women with and without endometrial cancer. J Clin Endocrinol Metab 1986;62:508-12.

22. Mollerstrom G, Carlstrom K, Lagrelius A, et al. Is there an altered steroid profile in patients with endometrial carcinoma? Cancer 1993;72:173-81.

23. Knab DR. Estrogen and endometrial carcinoma. Obstet Gynecol Surv 1977;32:267-81.

24. Tseng L, Mazella J, Funt Ml, et al. Preliminary studies of aromatase in human neoplastic endometrium. Obstet Gynecol 1984;63:150-4.

25. Wynder EL, Escher GC, Mantel N. An epidemiological investigation of cancer of the endometrium. Cancer 1966;19:489-520.

26. Hemsell DL, Grodin JM, Brenner PF, et al. Plasma precursors of estrogen. II. Correlation of the extent of conversion of plasma androstenedione to estrone with age. J Clin Endocrinol Metab 1974;38:476-9.

27. Southcott BM. Carcinoma of the endometrium. Drugs 2001;61:1395-405.

28. Lachance JA, Everett EN, Greer B, et al. The effect of age on clinical/pathologic features, surgical morbidity, and outcome in patients with endometrial cancer. Gynecol Oncol 2006;101:470-5.

29. Burbos N, Musonda P, Giarenis I, et al. Predicting the risk of endometrial cancer in postmenopausal women presenting with vaginal bleeding: the Norwich DEFAB risk assessment tool. Br J Cancer 2010;102:1201-6.

30. Allen NE, Key TJ, Dossus $L$, et al. Endogenous sex hormones and endometrial cancer risk in women in the European Prospective Investigation into Cancer and Nutrition (EPIC). Endocr Relat Cancer 2008;15:485-97.

31. Kirschner MA, Schneider G, Ertel NH, et al. Obesity, androgens, estrogens, and cancer risk. Cancer Res 1982;42(8 Suppl):3281-5.

32. Pettersson B, Bergstrom R, Johansson ED. Serum estrogens and androgens in women with endometrial carcinoma. Gynecol Oncol 1986;25:223-33.

33. Azziz R. Reproductive endocrinologic alterations in female asymptomatic obesity. Fertil Steril 1989;52:703-25.

34. Nyholm HC, Nielsen AL, Lyndrup J, et al. Plasma oestrogens in postmenopausal women with endometrial cancer. Br J Obstet Gynaecol 1993;100:1115-19.

35. Zeleniuch-Jacquotte A, Akhmedkhanov A, Kato I, et al. Postmenopausal endogenous oestrogens and risk of endometrial cancer: results of a prospective study. Br J Cancer 2001;84:975-81.

36. Lukanova A, Lundin E, Micheli A, et al. Circulating levels of sex steroid hormones and risk of endometrial cancer in postmenopausal women. Int $J$ Cancer 2004;108:425-32.

37. Chang RJ, Judd HL. The ovary after menopause. Clin Obstet Gynecol 1981;24:181-91.

38. Potischman N, Hoover RN, Brinton LA, et al. Case-control study of endogenous steroid hormones and endometrial cancer. J Natl Cancer Inst 1996;88:1127-35.

39. Aiman J. Age, estrogen, and the endometrium. Clin Obstet Gynecol 1981;24:193-202.

40. Tseng L, Mazella J, Mann WJ, et al. Estrogen synthesis in normal and malignant human endometrium. J Clin Endocrinol Metab 1982;55:1029-31.

41. Jongen VH, Hollema $\mathrm{H}$, Van Der Zee AG, et al. Aromatase in the context of breast and endometrial cancer. A review. Minerva Endocrinol 2006;31:47-60.

42. Fox $\mathbf{H}$, Sen DK. A controlled study of the constitutional stigmata of endometrial adenocarcinoma. Br J Cancer 1970:24:30-6.

43. Murphy LJ, Ghahary A. Uterine insulin-like growth factor-1: regulation of expression and its role in estrogen-induced uterine proliferation. Endocr Rev 1990;11:443-53.

44. Rose PG. Endometrial carcinoma. N Engl J Med 1996;335:640-9.

45. Weiss NS, Hill DA. Postmenopausal estrogens and progestogens and the incidence of gynecologic cancer. Maturitas 1996;23:235-9.

46. Emons G, Fleckenstein G, Hinney B, et al. Hormonal interactions in endometrial cancer. Endocr Relat Cancer 2000;7:227-42.

47. Lundberg V, Tolonen $\mathrm{H}$, Stegmayr B, et al. Use of oral contraceptives and hormone replacement therapy in the WHO MONICA project. Maturitas 2004;48:39-49.

48. Ziel HK, Finkle WD. Increased risk of endometrial carcinoma among users of conjugated estrogens. N Engl J Med 1975;293:1167-70.

49. Mack TM, Pike MC, Henderson BE, et al. Estrogens and endometrial cancer in a retirement community. N Engl J Med 1976;294:1262-7.

50. MacDonald PC, Edman CD, Hemsell DL, et al. Effect of obesity on conversion of plasma androstenedione to estrone in postmenopausal women with and without endometrial cancer. Am J Obstet Gynecol 1978;130:448-55.

51. Antunes CM, Strolley PD, Rosenshein NB, et al. Endometrial cancer and estrogen use. Report of a large case-control study. N Engl J Med 1979;300:9-13.

52. Grady D, Gebretsadik T, Kerlikowske K, et al. Hormone replacement therapy and endometrial cancer risk: a meta-analysis. Obstet Gynecol 1995;85:304-13.

53. Beresford SA, Weiss NS, Voigt LF, et al. Risk of endometrial cancer in relation to use of oestrogen combined with cyclic progestagen therapy in postmenopausal women. Lancet 1997;349:458-61.

54. Weiderpass E, Adami HO, Baron JA, et al. Use of oral contraceptives and endometrial cancer risk (Sweden). Cancer Causes Control 1999;10:277-84.

55. Beral V, Reeves G, Banks E. Current evidence about the effect of hormone replacement therapy on the incidence of major conditions in postmenopausal women. BJOG 2005;112:692-5.

56. Voigt LF, Weiss NS, Chu J, et al. Progestagen supplementation of exogenous oestrogens and risk of endometrial cancer. Lancet 1991;338:274-7.

57. Robertson WB. The Endometrium. London: Butterworths, 1981. 
58. Bergstrom A, Pisani P, Tenet V, et al. Overweight as an avoidable cause of cancer in Europe. Int J Cancer 2001;91:421-30.

59. Kaaks R, Lukanova A, Kurzer MS. Obesity, endogenous hormones, and endometrial cancer risk: a synthetic review. Cancer Epidemiol Biomarkers Prev 2002;11:1531-43.

60. Polednak AP. Trends in incidence rates for obesity-associated cancers in the US. Cancer Detect Prev 2003;27:415-21.

61. Bray $\mathbf{F}$, Loos AH, Oostindier $\mathrm{M}$, et al. Geographic and temporal variations in cancer of the corpus uteri: incidence and mortality in pre- and postmenopausal women in Europe. Int J Cancer 2005;117:123-31.

62. Reeves GK, Pirie K, Beral V, et al. Cancer incidence and mortality in relation to body mass index in the Million Women Study: cohort study. BMJ 2007; 335:1134

63. Lepine J, Audet-Walsh E, Gregoire $\mathrm{J}$, et al. Circulating estrogens in endometrial cancer cases and their relationship with tissular expression of key estrogen biosynthesis and metabolic pathways. J Clin Endocrinol Metab 2010;95:2689-98.

64. Niwa K, Murase T, Furui T, et al. Enhancing effects of estrogens on endometrial carcinogenesis initiated by $\mathrm{N}$-methyl- $\mathrm{N}$-nitrosourea in ICR mice. Jpn J Cancer Res 1993;84:951-5.

65. Sivridis $\mathbf{E}$, Giatromanolaki A. Proliferative activity in postmenopausal endometrium: the lurking potential for giving rise to an endometrial adenocarcinoma. J Clin Pathol 2004;57:840-4.

66. Archer DF, Mclntyre-Seltman K, Wilborn WW Jr, et al. Endometrial morphology in asymptomatic postmenopausal women. Am J Obstet Gynecol 1991;165:317-20; discussion 20-2

67. Korhonen MO, Symons JP, Hyde BM, et al. Histologic classification and pathologic findings for endometrial biopsy specimens obtained from 2964 perimenopausal and postmenopausal women undergoing screening for continuous hormones as replacement therapy (CHART 2 Study). Am J Obstet Gynecol 1997; 176:377-80.

68. Rance NE. Menopause and the human hypothalamus: evidence for the role of kisspeptin/neurokinin B neurons in the regulation of estrogen negative feedback. Peptides 2009;30:111-22.

69. Zaino RJ. Interpretation of Endometrial Biopsies and Curettings. Philadelphia: Lippincott-Raven, 1996.

70. Speroff L, Glass R, Kase N. Clinical Gynecological Endocrinology and Infertility. 5th edn. Baltimore: Williams and Wilikins, 1994.

71. Reyes FI, Winter JS, Faiman C. Pituitary-ovarian relationships preceding the menopause. I. A cross-sectional study of serum follice-stimulating hormone, luteinizing hormone, prolactin, estradiol, and progesterone levels. Am J Obstet Gynecol 1977;129:557-64.

72. Overlie I, Morkrid L, Andersson AM, et al. Inhibin A and B as markers of menopause: a five-year prospective longitudinal study of hormonal changes during the menopausal transition. Acta Obstet Gynecol Scand 2005:84:281-5.

73. Buckley CH, Fox H. Biopsy Pathology of the Endometrium. 2nd edn. London: Arnold, 2002.

74. Snijders MP, de Goeij AF, Debets-Te Baerts MJ, et al. Immunocytochemical analysis of oestrogen receptors and progesterone receptors in the human uterus throughout the menstrual cycle and after the menopause. J Reprod Fertil 1992:94:363-71.

75. Noci I, Borri P, Scarselli G, et al. Morphological and functional aspects of the endometrium of asymptomatic post-menopausal women: does the endometrium really age? Hum Reprod 1996;11:2246-50.

76. Kurman RJ, Kaminski PF, Norris HJ. The behavior of endometrial hyperplasia. A long-term study of 'untreated' hyperplasia in 170 patients. Cancer 1985:56:403-12.

77. Mutter GL, Zaino RJ, Baak JP, et al. Benign endometrial hyperplasia sequence and endometrial intraepithelial neoplasia. Int J Gynecol Pathol 2007:26:103-14.

78. Spiegel GW. Endometrial carcinoma in situ in postmenopausal women. Am J Surg Pathol 1995; 19:417-32.

79. Zheng W, Liang SX, Yu H, et al. Endometrial glandular dysplasia: a newly defined precursor lesion of uterine papillary serous carcinoma. Part I: morphologic features. Int J Surg Pathol 2004:12:207-23.

80. Sivridis E, Giatromanolaki A. Prognostic aspects on endometrial hyperplasia and neoplasia. Virchows Arch 2001;439:118-26.

81. Sivridis $\mathbf{E}$, Giatromanolaki A, Liberis $\mathrm{V}$, et al. Autophagy in endometrial carcinomas and prognostic relevance of 'stone-like' 'structures (SLS). What is destined for the atypical endometrial hyperplasia? Autophagy 2011;7:74-82.

82. Fadare $\mathbf{0}$, Zheng $\mathbf{W}$. Insights into endometrial serous carcinogenesis and progression. Int J Clin Exp Pathol 2009;2:411-32.

83. Creasman WT, Kohler MF, Odicino F, et al. Prognosis of papillary serous, clear cell, and grade 3 stage I carcinoma of the endometrium. Gynecol Oncol 2004;95:593-6.

84. Clement PB, Young RH. Non-endometrioid carcinomas of the uterine corpus: a review of their pathology with emphasis on recent advances and problematic aspects. Adv Anat Pathol 2004;11:117-42.

85. Hamilton CA, Cheung MK, Osann K, et al. Uterine papillary serous and clear cell carcinomas predict for poorer survival compared to grade 3 endometrioid corpus cancers. Br J Cancer 2006;94:642-6.

86. Faratian D, Stillie A, Busby-Earle RM, et al. A review of the pathology and management of uterine papillary serous carcinoma and correlation with outcome. Int J Gynecol Cancer 2006;16:972-8.
87. Mendivil A, Schuler KM, Gehrig PA. Non-endometrioid adenocarcinoma of the uterine corpus: a review of selected histological subtypes. Cancer Control 2009:16:46-52.

88. Mazur MT, Kurman RJ. Diagnosis of Endometrial Biopsies and Curettings. A Practical Approach. New York: Springer, 1995.

89. Abeler VM, Kjorstad KE. Endometrial adenocarcinoma in Norway. A study of a total population. Cancer 1991;67:3093-103.

90. Kuwabara Y, Susumu N, Banno K, et al. Clinical characteristics of prognostic factors in poorly differentiated (G3) endometrioid adenocarcinoma in Japan. Jpn $J$ Clin Oncol 2005;35:23-7.

91. Matthews RP, Hutchinson-Colas J, Maiman M, et al. Papillary serous and clear cell type lead to poor prognosis of endometrial carcinoma in black women. Gynecol Oncol 1997;65:206-12.

92. Christopherson WM, Alberhasky RC, Connelly PJ. Carcinoma of the endometrium. II. Papillary adenocarcinoma: a clinical pathological study, 46 cases. Am J Clin Pathol 1982;77:534-40.

93. Hendrickson M, Ross J, Eifel P, et al. Uterine papillary serous carcinoma: a highly malignant form of endometrial adenocarcinoma. Am J Surg Pathol 1982;6:93-108.

94. Kato DT, Ferry JA, Goodman A, et al. Uterine papillary serous carcinoma (UPSC): a clinicopathologic study of 30 cases. Gynecol Oncol 1995;59:384-9.

95. Malpica A, Tornos C, Burke TW, et al. Low-stage clear-cell carcinoma of the endometrium. Am J Surg Pathol 1995;19:769-74.

96. Slomovitz BM, Burke TW, Eifel PJ, et al. Uterine papillary serous carcinoma (UPSC): a single institution review of 129 cases. Gynecol Oncol 2003;91:463-9.

97. Sagr ER, Denschlag D, Kerim-Dikeni A, et al. Prognostic factors and treatmentrelated outcome in patients with uterine papillary serous carcinoma. Anticancer Res 2007:27:1213-17.

98. Benito V, Lubrano A, Arencibia 0 , et al. Pure papillary serous tumors of the endometrium: a clinicopathological analysis of 61 cases from a single institution. Int J Gynecol Cancer 2009:19:1364-9.

99. Murphy KT, Rotmensch J, Yamada SD, et al. Outcome and patterns of failure in pathologic stages I-IV clear-cell carcinoma of the endometrium: implications for adjuvant radiation therapy. Int J Radiat Oncol Biol Phys 2003;55:1272-6.

100. Abeler VM, Vergote IB, Kjorstad KE, et al. Clear cell carcinoma of the endometrium. Prognosis and metastatic pattern. Cancer 1996;78:1740-7.

101. Abeler VM, Kjorstad KE, Nesland JM. Undifferentiated carcinoma of the endometrium. A histopathologic and clinical study of 31 cases. Cancer 1991:68:98-105

102. Altrabulsi B, Malpica A, Deavers MT, et al. Undifferentiated carcinoma of the endometrium. Am J Surg Pathol 2005;29:1316-21.

103. Soslow RA, Bissonnette JP, Wilton A, et al. Clinicopathologic analysis of 187 highgrade endometrial carcinomas of different histologic subtypes: similar outcomes belie distinctive biologic differences. Am J Surg Pathol 2007;31:979-87.

104. Sivridis E, Giatromanolaki A. Endometrial adenocarcinoma: beliefs and scepticism. Int J Surg Pathol 2004;12:99-105.

105. Clarke BA, Gilks CB. Endometrial carcinoma: controversies in histopathological assessment of grade and tumour cell type. J Clin Pathol 2010;63:410-15.

106. Sivridis E, Giatromanolaki A. Endometrial adenocarcinoma: an apostasy from early views. Gynecol Oncol 2004:95:772-3.

107. Zaino RJ. FIGO staging of endometrial adenocarcinoma: a critical review and proposal. Int J Gynecol Pathol 2009;28:1-9.

108. Gemer $\mathbf{0}$, Uriev L, Voldarsky $\mathrm{M}$, et al. The reproducibility of histological parameters employed in the novel binary grading systems of endometrial cancer. Eur J Surg Oncol 2009;35:247-51.

109. Alkushi A, Abdul-Rahman ZH, Lim P, et al. Description of a novel system for grading of endometrial carcinoma and comparison with existing grading systems. Am J Surg Pathol 2005:29:295-304.

110. Scholten AN, Smit VT, Beerman $\mathrm{H}$, et al. Prognostic significance and interobserver variability of histologic grading systems for endometrial carcinoma. Cancer 2004; 100:764-72.

111. Lax SF, Kurman RJ, Pizer ES, et al. A binary architectural grading system for uterine endometrial endometrioid carcinoma has superior reproducibility compared with FIGO grading and identifies subsets of advance-stage tumors with favorable and unfavorable prognosis. Am J Surg Pathol 2000;24:1201-8.

112. Taylor RR, Zeller J, Lieberman RW, et al. An analysis of two versus three grades for endometrial carcinoma. Gynecol Oncol 1999;74:3-6.

113. Melhem MF, Tobon H. Mucinous adenocarcinoma of the endometrium: a clinicopathological review of 18 cases. Int J Gynecol Pathol 1987;6:347-55.

114. Lax SF, Pizer ES, Ronnett BM, et al. Comparison of estrogen and progesterone receptor, Ki-67, and p53 immunoreactivity in uterine endometrioid carcinoma and endometrioid carcinoma with squamous, mucinous, secretory, and ciliated cell differentiation. Hum Pathol 1998;29:924-31.

115. Lax SF. Molecular genetic pathways in various types of endometrial carcinoma: from a phenotypical to a molecular-based classification. Virchows Arch 2004:444:213-23

116. Ross JC, Eifel PJ, Cox RS, et al. Primary mucinous adenocarcinoma of the endometrium. A clinicopathologic and histochemical study. Am J Surg Pathol 1983; 7:715-29.

117. Tashiro $\mathbf{H}$, Blazes MS, Wu R, et al. Mutations in PTEN are frequent in endometrial carcinoma but rare in other common gynecological malignancies. Cancer Res 1997:57:3935-40. 
118. Risinger Jl, Hayes K, Maxwell GL, et al. PTEN mutation in endometrial cancers is associated with favorable clinical and pathologic characteristics. Clin Cancer Res 1998;4:3005-10

119. Bussaglia $\mathbf{E}$, del Rio E, Matias-Guiu X, et al. PTEN mutations in endometrial carcinomas: a molecular and clinicopathologic analysis of 38 cases. Hum Pathol 2000;31:312-17.

120. Mutter GL, Lin MC, Fitzgerald JT, et al. Altered PTEN expression as a diagnostic marker for the earliest endometrial precancers. J Natl Cancer Inst 2000;92:924-30.

121. Caduff RF, Johnston CM, Frank TS. Mutations of the Ki-ras oncogene in carcinoma of the endometrium. Am J Pathol 1995;146:182-8.

122. Lax SF, Kendall B, Tashiro $\mathrm{H}$, et al. The frequency of p53, K-ras mutations, and microsatellite instability differs in uterine endometrioid and serous carcinoma: evidence of distinct molecular genetic pathways. Cancer 2000;88:814-24.

123. Lagarda H, Catasus $L$, Arguelles $R$, et al. K-ras mutations in endometrial carcinomas with microsatellite instability. J Pathol 2001:193:193-9.

124. Tashiro H, Lax SF, Gaudin PB, et al. Microsatellite instability is uncommon in uterine serous carcinoma. Am J Pathol 1997;150:75-9.

125. Catasus L, Machin P, Matias-Guiu X, et al. Microsatellite instability in endometrial carcinomas: clinicopathologic correlations in a series of 42 cases. Hum Pathol 1998:29:1160-4.

126. Maxwell GL, Risinger Jl, Hayes KA, et al. Racial disparity in the frequency of PTEN mutations, but not microsatellite instability, in advanced endometrial cancers. Clin Cancer Res 2000:6:2999-3005.

127. Maxwell GL, Risinger Jl, Alvarez AA, et al. Favorable survival associated with microsatellite instability in endometrioid endometrial cancers. Obstet Gynecol 2001:97:417-22

128. Rosenberg $\mathbf{P}$, Wingren $\mathrm{S}$, Simonsen $\mathrm{E}$, et al. Flow cytometric measurements of DNA index and S-phase on paraffin-embedded early stage endometrial cancer: an important prognostic indicator. Gynecol Oncol 1989;35:50-4.

129. Prat J, Oliva E, Lerma E, et al. Uterine papillary serous adenocarcinoma. A 10-case study of p53 and c-erbB-2 expression and DNA content. Cancer 1994:74:1778-83.

130. Pradhan M, Abeler VM, Danielsen HE, et al. Image cytometry DNA ploidy correlates with histological subtypes in endometrial carcinomas. Mod Pathol 2006;19:1227-35.

131. Sherman ME, Bur ME, Kurman RJ. p53 in endometrial cancer and its putative precursors: evidence for diverse pathways of tumorigenesis. Hum Patho 1995;26:1268-74.

132. Tashiro $\mathbf{H}$, Isacson $\mathrm{C}$, Levine $\mathrm{R}$, et al. p53 gene mutations are common in uterine serous carcinoma and occur early in their pathogenesis. Am J Pathol 1997; 150:177-85.
133. Kovalev S, Marchenko ND, Gugliotta BG, et al. Loss of p53 function in uterine papillary serous carcinoma. Hum Pathol 1998;29:613-19.

134. Halperin R, Zehavi S, Habler L, et al. Comparative immunohistochemical study of endometrioid and serous papillary carcinoma of endometrium. Eur J Gynaecol Oncol 2001;22:122-6

135. Jia L, Liu Y, Yi X, et al. Endometrial glandular dysplasia with frequent p53 gene mutation: a genetic evidence supporting its precancer nature for endometrial serous carcinoma. Clin Cancer Res 2008;14:2263-9.

136. Lax SF. Molecular genetic changes in epithelial, stromal and mixed neoplasms of the endometrium. Pathology 2007;39:46-54.

137. Kohler MF, Berchuck A, Davidoff AM, et al. Overexpression and mutation of p53 in endometrial carcinoma. Cancer Res 1992;52:1622-7.

138. Pere H, Tapper J, Wahlstrom T, et al. Distinct chromosomal imbalances in uterine serous and endometrioid carcinomas. Cancer Res 1998;58:892-5.

139. Risinger JI, Berchuck A, Kohler MF, et al. Mutations of the E-cadherin gene in human gynecologic cancers. Nat Genet 1994;7:98-102.

140. Jeanes A, Gottardi CJ, Yap AS. Cadherins and cancer: how does cadherin dysfunction promote tumor progression? Oncogene 2008;27:6920-9.

141. Singh M, Spoelstra NS, Jean A, et al. ZEB1 expression in type I vs type II endometrial cancers: a marker of aggressive disease. Mod Pathol 2008:21:912-23.

142. Holcomb K, Delatorre R, Pedemonte B, et al. E-cadherin expression in endometrioid, papillary serous, and clear cell carcinoma of the endometrium. Obstet Gynecol 2002;100:1290-5

143. Mell LK, Meyer JJ, Tretiakova M, et al. Prognostic significance of E-cadherin protein expression in pathological stage I-III endometrial cancer. Clin Cancer Res 2004:10:5546-53

144. Stefansson IM, Salvesen HB, Akslen LA. Prognostic impact of alterations in P-cadherin expression and related cell adhesion markers in endometrial cancer. $\mathrm{J}$ Clin Oncol 2004;22:1242-52.

145. Announcements. FIGO stages - 1988 revision. Gynecol Oncol 1989;35:125-7

146. Zaino RJ, Kurman RJ, Diana KL, et al. The utility of the revised Internationa Federation of Gynecology and Obstetrics histologic grading of endometrial adenocarcinoma using a defined nuclear grading system. A Gynecologic Oncology Group study. Cancer 1995:75:81-6.

147. Moreno-Bueno G, Hardisson D, Sanchez C, et al. Abnormalities of the APC/betacatenin pathway in endometrial cancer. Oncogene 2002;21:7981-90.

148. Fukuchi T, Sakamoto M, Tsuda $\mathrm{H}$, et al. Beta-catenin mutation in carcinoma of the uterine endometrium. Cancer Res 1998;58:3526-8.

149. Machin P, Catasus L, Pons C et al. CTNNB1 mutations and beta-catenin expression in endometrial carcinomas. Hum Pathol 2002;33:206-12. 